\title{
Da razão à performance: a educação sob a constituição do pós- humano na era da internet ubíqua
}

\author{
De la razón a la performance: la educación bajo la constitución del post- \\ humano en la era de internet ubicua
}

From reason to performance: education under the constitution of post-
human in the ubiquitous internet era

\author{
Otávio Iost Vinhas ${ }^{1}$ \\ Helena Jungblut ${ }^{2}$ \\ Rafael Peduzzi Gomes ${ }^{3}$
}

\begin{abstract}
Resumo
Desde a popularização da internet na década de 1990, é notório o esforço de diversos autores na tentativa de descrever e refletir acerca das mudanças provocadas pelo desenvolvimento de novas ferramentas midiáticas no âmbito da educação e cultura. Hoje, há um interseccionamento entre as ditas dimensões do "real" e do "virtual", em um movimento de constante transformação nos espaçotemporais vivenciados pelo humano diante da constituição dos fatos, da figura de si mesmo e do outro. Nesse sentido, o presente trabalho problematiza as abordagens empregadas pelas práticas curriculares tradicionais diante do contexto sociotécnico contemporâneo. Desse modo, questionamos, em que medida os materiais escolares, bem como as estratégias de ensino, correspondem com a formação informal de um "novo" sujeito, isto é, em reconhecimento à ubiquidade da internet e da influência das tecnologias digitais na cultura contemporânea. Entendemos, sob uma ótica do "póshumano", que o advento das novas mídias provoca modificações fundamentais na maneira em que o sujeito observa e interage com o mundo, culminando em novos modelos de articulação entre pensamento e linguagem. Assim, podemos repensar, paradigmaticamente, a educação e a construção contemporânea do conhecimento como objetos concebidos por sujeitos constituídos enquanto criação colaborativa entre humanos, objetos nãohumanos e relações mediadas.
\end{abstract}

Palavras-Chave: pós-humano; educação; tecnologias digitais.

\section{Resumen}

Desde la popularización de internet en la década de 1990, es notorio el esfuerzo de diversos autores en el intento de describir y reflexionar acerca de los cambios provocados por el desarrollo de nuevas herramientas mediáticas en el ámbito de la educación y la cultura. Hoy, hay un cruzamiento entre las dichas dimensiones del "real" y del "virtual", en un movimiento de constante transformación en los espaciotemporales vivenciados por el humano ante la constitución de los hechos, de la figura de sí mismo y del otro. En este sentido, el presente trabajo problematiza los enfoques empleados por las prácticas curriculares tradicionales ante el contexto sociotécnico contemporáneo. De ese modo, cuestionamos, en qué medida los materiales escolares, así como las estrategias de enseñanza, corresponden con la formación informal de un "nuevo" sujeto, es decir, en reconocimiento a la ubicuidad de internet y de la influencia de las tecnologías digitales en la cultura contemporánea. Comprendemos, bajo la óptica del "post-humano", que el advenimiento de los nuevos medios provoca modificaciones

\footnotetext{
${ }^{1}$ Mestrando em Sociologia; Bolsista CAPES; Universidade Federal de Pelotas (UFPEL); otavio.vinhas@gmail.com

${ }^{2}$ Mestranda em Letras, Bolsista CAPES/CNPq; Universidade de Santa Cruz do Sul (UNISC); le.jungblut@gmail.com

${ }^{3}$ Mestre em Design pela UniRitter; Professor nos cursos de Design Gráfico e Design Digital da Universidade Federal de Pelotas (UFPEL); rafaelpeduzzi@gmail.com
} 
fundamentales en la manera en que el sujeto observa e interactúa con el mundo, culminando en nuevos modelos de articulación entre pensamiento y lenguaje. Así, podemos repensar, paradigmáticamente, la educación y la construcción contemporánea del conocimiento como objetos concebidos por sujetos constituidos como creación colaborativa entre humanos, objetos no humanos y relaciones mediadas.

Palabras claves: post-humano; educación; tecnologías digitales.

\begin{abstract}
Since the popularization of the internet in the 1990s, it`s notorious the effort of several authors in the attempt to describe and reflect on the changes brought by the development of new media tools in the field of education and culture. Today, there is an intersection between the considered dimensions of the "real" and the "virtual", followed by a movement of constant transformation in the space-time experienced by the humans in relation to the constitution of the facts, to their own image and to the figure of the other. In this sense, the present work problematizes the approaches used by the traditional curricular practices forward the contemporary sociotechnical context. Hence, we question the extent to which school materials as well as teaching strategies correspond to the informal formation of a "new" subject, that is, in recognition of the ubiquity of the internet and the influence of digital technologies on the contemporary culture. We understand, anchored in a "post-human" perspective, that the advent of new media causes fundamental changes in the way the subject observes and interacts with the world, culminating in new models of articulation between thought and language. Thus, we can rethink, paradigmatically, education and the contemporary construction of knowledge as objects conceived by subjects constituted in a collaborative dynamic, created by the correlation between humans, nonhuman objects and mediated relations.
\end{abstract}

Keywords: post-human; education; digital technologies.

\title{
1. Introdução
}

Sala de aula. Que lugar é esse? Um ambiente dentro de outro ambiente que se chama escola. Ambos os lugares recebem um número considerável de questionamentos e definições por pesquisas universais. Muitos explicam a função da sala, da aula, o motivo de existência, a importância ou a desimportância, alguns inclusive protestam pela extrapolação ou extinção dela. Poderíamos chamar a sala em que acontece uma aula como um lugar de encontro? Encontro de corpos, culturas, vivências, pensamentos, linguagens, vozes. Lugar onde tudo isso pode vir a encorpar-se, “encarnar-se”. O pensador Jorge Larrosa Bondía (2017), em diálogo com María Zambrano, fala da sala de aula como lugar da voz, pois é a partir de uma voz que alunos e professores se fazem presentes, seja nas palavras ou nos silêncios. Contudo, muitas vezes, o escutar, dentro da sala de aula, se relaciona à passividade, ao aborrecimento, à esterilidade de uma memória ou representa a impossibilidade de um sujeito contemporâneo passar mais de vinte minutos em silêncio sem mexer no celular. E como tudo isso acontece? Eis outra questão muito discutida: é o método, os procedimentos, a transmissão.

Num contexto de educação básica, por exemplo, é comum os alunos referenciarem aulas como as de gramática ou matemática como "chatas", justamente por serem baseadas em normas, regras e, normalmente, apresentarem um sujeito principal detentor do conhecimento: 
o professor. Não cabe a nós discutir aqui qual metodologia é a correta ou não, mas o que tem sido feito em um contexto que já vem mudando gradativamente, especialmente por estudos que partem do século XX e por professores que buscam definir metodologias heterogêneas, que colocam o aluno como sujeito proativo, envolvido em atividades mais complexas, em que tenha de tomar decisões, avaliar resultados, criar e experienciar novos materiais.

A metodologia escolar sempre traz, consigo, o contexto. $\mathrm{O}$ contexto, pelo menos dos anos 2000 até o presente, é a comunicação entre grupos, nas redes sociais, que compartilham interesses, vivências, pesquisas e aprendizagens. É, então, axiomático pensar em tecnologias digitais e internet dentro da sala de aula. José Moran diz que "cada vez mais a educação se horizontaliza e se expressa em múltiplas interações grupais e personalizadas” (2015, p. 26), isto é, as tecnologias em rede "nos permitem não só trazer o bairro e a cidade, mas também o mundo inteiro, em tempo real, com suas múltiplas ideias, pessoas e acontecimentos numa troca intensa, rica e ininterrupta" (MORAN, 2015, p. 25). Ao passo que a sala de aula é um lugar fechado, a internet produz a ideia de um "local” aberto, descentralizado - com ela, as paredes das escolas e das universidades se tornam invisíveis, as pessoas se comunicam, trocam informações e pesquisas. Cumprem uma função primeira que é parecida à função escolar: compartilhar e construir conhecimento.

A tecnologia não é separada do humano — podemos, inclusive, trazer à luz a máxima mcluhaniana de que "as mídias são extensões do homem" para pensar que, ao longo da história, tanto a educação não-escolar como a própria escola sempre fizeram uso de tecnologias: o pergaminho, o papiro, o livro manuscrito, o papel, a tipografia, o livro impresso, o rádio, a televisão, o vídeo e até tecnologias como o giz, o lápis e o pincel. A questão é refletirmos como as tecnologias mais recentes podem ser e são incorporadas com a mesma naturalidade que se fez o livro, por exemplo.

Isto é, de um lado temos uma rede de colaboração entre professores e pesquisadores com planos pedagógicos criativos e inovadores - que incluem, por exemplo, fanfics dentro de aulas de Literatura, softwares no aprendizado da Matemática, a publicidade nas aulas de Língua Portuguesa, ou o jornalismo no ensino de História, enfim, a gama é grande e o principal meio de encontrar é, justamente, a internet. Contudo, de outro lado, temos um contexto escolar que não parece se modificar paradigmaticamente — dentro da sala de aula, atividades criativas, fora dela, o mesmo modelo e grade curricular há mais de séculos, fora da sala de aula, alunos imersos em uma rede online, aprendendo diversos assuntos pelo YouTube, dentro da sala de aula, conteúdos que não alcançam a complexificação das redes. É a partir desse pressuposto que nasceu o questionamento para este estudo: como pensar o sujeito pós-humano 
nas relações de aprendizado? O que fazemos com o ensino de temas como a ditadura quando, na internet, o aluno aprende que o acontecimento nunca existiu? À primeira vista, poderíamos contestar dizendo que temos de compreender o sujeito em seu contexto.

Assim, metodologicamente, este estudo pode ser caracterizado como qualitativo, de alcance exploratório, com base em pesquisa bibliográfica e com um caráter de reflexão teórica. O enfoque qualitativo envolve um pesquisador que investiga o mundo social e "desenvolve uma teoria coerente com os dados, de acordo com aquilo que observa" (SAMPIERI; COLLADO; LUCIO, 2013, p. 33), num processo indutivo de explorar e descrever, indo do particular ao geral. Já o alcance exploratório, ainda segundo os autores, envolve estudos que examinam um tema ou problema de pesquisa pouco estudado, sobre o qual ainda há dúvidas ou de que ainda se está delineando a abordagem. Nesse sentido, estabelecemos em nossa problematização a intenção de levantar mais informações e questões a fim de realizar uma pesquisa mais completa num contexto particular, bem como "identificar conceitos ou variáveis promissoras, estabelecer prioridades para pesquisas futuras" (SAMPIERI; COLLADO; LUCIO, 2013, p. 101).

Diante do exposto, o artigo se estrutura primeiramente em dois grandes eixos, que tratam da construção do sujeito pós-humano face à indistinção online/offline na era da internet ubíqua (seção 2) e das abordagens empregadas por práticas curriculares tradicionais diante do contexto sociotécnico contemporâneo (seção 3). Por fỉm, são expostas as considerações finais (seção 4), em um questionamento, a partir dos conceitos de razão e performance, de como as transformações na relação da educação com as tecnologias podem se dar em um nível paradigmático. A seguir, fazemos uma abordagem do contexto que envolve tecnologia, internet e sociedade na cultura contemporânea.

\section{A internet ubíqua e o advento do pós-humano: a construção do sujeito face à indistinção online/offline}

A ampliação do acesso à internet, sobretudo desde que sua infraestrutura técnica passou a ser gerenciada pelo setor privado, vem provocando transformações basilares nos mais diversos campos das relações societárias (CASTELLS, 2011). Desde então, podemos perceber que a progressiva incorporação de dispositivos informacionais permanentemente conectados a uma dimensão virtual (digital) no cotidiano tem demandado a proposição de novas diretrizes explicativas acerca de uma sociedade em constante mutação. Nota-se que, quando falamos de um cenário sociopolítico global fortemente interconectado culturalmente 
(CASTELLS, 2015) ${ }^{4}$, pressupomos estarmos diante de um cenário caracterizado pela indeterminação no que diz respeito às origens e aos possíveis rumos propiciados pela imersão tecnológica na sociedade.

Embora já exista uma vasta e crescente literatura científica dedicada à interrelação entre tecnologia, internet e sociedade na área das ciências humanas de modo geral, ressaltamos que essa temática constitui um objeto complexo, o qual exige ao pesquisador, como prerrogativa de investigação, um esforço simultaneamente atento, contínuo e flexível. Sem a pretensão de esgotar — ou mesmo de contemplar — teoricamente as diversas abordagens possíveis para um fenômeno essencialmente multifacetado, destacamos nesta seção alguns aspectos concernentes à ideia de construção do sujeito contemporâneo. Dessa forma, constatamos a existência de um entrelaçamento entre as ditas dimensões do "real" e do "virtual", em um movimento de constante transformação nos espaços temporais vivenciados pelo humano diante da constituição dos fatos, da figura de si mesmo e do outro.

A ubiquidade da internet na sociedade caracteriza-se pela assunção, por parte dos sujeitos em suas vivências cotidianas, de que existe uma extensão virtual da realidade, mediada por dispositivos informacionais, no âmbito das relações físicas. Assim, não necessariamente todas as pessoas devem estar conectadas à internet para que a presença do mundo digital seja percebida de forma generalizada. Por sua vez, as relações mediadas no ambiente da internet pressupõem, direta ou indiretamente, a existência de um real "físico", no seu sentido concreto e factual. Desse modo, distanciando-se de uma perspectiva essencialista e/ou meramente binária quanto à percepção destes "reais" ao sujeito, entendemos que a noção de realidade encontra-se aproximada do que Richard Miskolci (2016, p. 284) classifica como "contínuo on-offline". Portanto, conforme o termo indica, constatamos que as diferentes formas de mediação — estejam estas manifestadas no plano físico ou na internet encontram-se reciprocamente vinculadas à forma como a realidade se apresenta ao sujeito, tornando improvável a possibilidade de uma separação material entre o que é real e o que é virtual/digital.

\footnotetext{
${ }^{4}$ Manuel Castells (2015, p. 172) menciona, sob a ótica do seu conceito de "autocomunicação de massa", que a expansão das tecnologias digitais para todos os níveis da sociedade favorece o surgimento de uma cultura comum, compartilhada globalmente, definida por quatro características básicas: 1) o consumismo; 2) o individualismo; 3) o cosmopolitismo; 4) o multiculturalismo.

${ }^{5}$ Nesse sentido, seguimos a lógica descrita por Léo Rodrigues (2010, p. 181). O autor entende a dimensão do real como "toda e qualquer experiência compartilhada por grupos sociais, independentes do tempo e do espaço". Nesse sentido, o real pode ser descrito através de três naturezas distintas: concreta, abstrata e virtual. Posteriormente, Rodrigues inclui outras três dimensões vinculadas ao "real", as quais podem ser apreendidas pela ciência como objeto de estudo: a) o real factual; b) o real simbólico; c) o real imagético.
} 
O conceito de "ciberespaço", nesta diretriz, conforme descrito por Pierre Lévy (1999) como “o espaço de comunicação aberto pela interconexão mundial dos computadores e das memórias dos computadores", não corresponderia a uma esfera espacial alheia à experiência humana da "realidade física", mas complementar a ela. Segundo André Lemos (2006), a ideia de cibercultura ${ }^{6}$ é um conceito associado a essa modificação da forma como a realidade é experienciada. Conforme aponta o autor, as redes planetárias propiciadas pela internet provocam transformações na percepção humana do espaço-tempo, ocasionada por movimentos de desterritorializações e de reterritorializações informacionais. Nessa ótica, a dinâmica social do ciberespaço é reconhecida como transgressora dos sentidos sobre a realidade formados exclusivamente no mundo físico. Na medida em que as disputas de poder na sociedade, no que diz respeito à hierarquias, significados e controle são transpostas e coarticuladas sob a mediação de dispositivos informacionais conectados à internet, o ciberespaço permite aos sujeitos um olhar para novas formas de constituírem-se, subjetivamente, frente à realidade.

A mediação entre o pensamento e a linguagem na sua interação com o real digital é articulada através de maneiras próprias, inerentes às regras e às ferramentas particulares do ciberespaço. Nesse sentido, Dresner e Herring (2012) utilizam o conceito de "discurso mediado por computador" (DMC) ao concordar que, apesar de constituírem-se através de recursos diferentes, as mesmas construções materiais vistas no mundo físico encontram respaldo nas relações online ${ }^{7}$. As características diferenciais da articulação entre o pensamento e a linguagem nessa situação correspondem, portanto, à arquitetura específica do espaço de sociabilidade (em uma determinada plataforma de mídia social, por exemplo, como o Facebook) inserido no ciberespaço. Conforme exemplifica Boyd (2014), sujeitos se comunicam diferentemente se estão interagindo ao redor de uma mesa ou se estão realizando contato por meio de uma janela fechada. Dessa forma, as possibilidades articulatórias do sujeito de se constituir informacionalmente/identitariamente e de se comunicar e estabelecer relações com outros intercorrem de acordo com as capacidades particulares do espaço em que estão inseridas.

\footnotetext{
6 De acordo com André Lemos e Pierre Lévy, a cibercultura é "o conjunto tecnocultural emergente no final do século XX impulsionado pela sociabilidade pós-moderna em sinergia com a microinformática e o surgimento das redes telemáticas mundiais; uma forma sociocultural que modifica hábitos sociais, práticas de consumo cultural, ritmos de produção e distribuição da informação, criando novas relações no trabalho e no lazer, novas formas de sociabilidade e de comunicação social” (LEVY \& LEMOS, 2008).

${ }^{7}$ Dresner e Herring (2012) utilizam como exemplo os "emoticons". Segundo eles, tratam-se de indicadores nãoverbais de emoção, representados na forma de rostos humanos.
} 
A concepção do pós-humano situa-se justamente nessa lógica de transformação da experiência do humano com a(s) realidade(s), entendendo-o como um sujeito permanentemente associado a dispositivos acoplados ao corpo. Assim, não por acaso, os debates políticos contemporâneos a respeito das chamadas bolhas de opinião (PARISER, 2012) ou "câmaras de eco" (SUNSTEIN, 2001) são pautados pela relação entre a economia da informação na internet e a autodeterminação do sujeito no estabelecimento das suas redes. Conforme aponta Lemos (2009), através da coleta e do tratamento de grandes quantidades de dados — produzidos simultaneamente em espaços digitais e físicos — por plataformas digitais, não raro ocorre de um determinado sujeito se encontrar, intencionalmente ou não, isolado informacionalmente de determinados conteúdos. Nesse caso específico, as plataformas digitais, baseadas na lógica operacional da Web 2.0 $0^{8}$, interagem continuamente com o usuário, de modo a propiciar, com base nos dados fornecidos pelo próprio usuário no curso das suas atividades online, conteúdos previamente filtrados, com o propósito de melhor atender às expectativas do sujeito 9 .

Figurativamente, podemos enxergar a representação ficcional do pós-humano através da estética ciborgue. Nela, organismos biológicos e máquinas acoplam-se, formando um ser híbrido. Em seu "Manifesto Ciborgue", a autora Donna Haraway (2016) destaca que as biotecnologias e as tecnologias da comunicação, sustentadas pelo discurso científico, são as duas ferramentas cruciais para o remodelamento dos corpos humanos para a forma de ciborgues. Nesse sentido, Lúcia Santaella (2007) afirma que as raízes ficcionais do póshumano são oriundas do movimento cyberpunk $^{10}$, o qual já produzia obras, no campo da literatura, baseadas na implantação de microtecnologias ao corpo humano.

$\mathrm{Na}$ esteira de um argumento crítico de viés não-essencialista a respeito da dicotomia humano-máquina, Santaella concebe o advento do pós-humano a partir de uma evolução

\footnotetext{
${ }^{8}$ Segundo Tim O'Reilly (2007), criador da expressão, a Web 2.0 corresponde à predominância das plataformas de serviço na internet como propiciadoras das conexões entre os indivíduos em redes. Assim, essas plataformas se destacam por utilizarem softwares de atualizações contínuas, isto é, que interagem continuamente com os seus perfis de seus usuários, com o intuito de promover a estes uma melhor experiência baseada nos seus gostos e interesses particulares.

${ }^{9}$ Embora não seja o foco deste trabalho, entendemos que a configuração material da internet possui implicações no modo como o sujeito desenvolve as suas relações mediadas no ambiente digital. Entendemos a internet como uma ferramenta sobretudo sociotécnica, isto é, cuja constituição material é moldada por uma conjuntura de relações políticas, sociais, econômicas e culturais. Sob perspectivas diversas, autores como Castells (2015), O’Hara e Hall (2018) e DeNardis (2014), trazem esta discussão.

10 André Lemos (2001) descreve que o movimento cyberpunk nasceu no final dos anos de 1960, a partir da atitude de jovens pessimistas em relação ao avanço da tecnologia na sociedade. Desempenhando técnicas de constrangimento à autoridade e às hierarquias de poder, em prol do livre acesso à informação, esses jovens fomentavam a apropriação individual das tecnologias, com a intenção de estimular a atitude punk do "faça você mesmo" para dissuadir o controle tecnológico, permitindo ao indivíduo o controle do seu próprio destino.
} 
linear, na qual diferentes dispositivos — não necessariamente tecnológicos — provocam um aumento das capacidades simbólicas e cognitivas do humano. Sem desassociar a evolução tecnológica da evolução biológica, podemos entender, conforme assevera a autora, que aptidões humanas como a fala e a escrita, assim como o acoplamento ao corpo de chips de memória conectados à internet, são dispositivos, isto é, são artificialidades utilizadas como extensões do corpo e da mente humana. No escopo da sua perspectiva crítica, a autora afirma:

\begin{abstract}
"pós-humano, este entendido não só como resultado dessas transformações, mas, sobretudo, como desconstrução das certezas ontológicas e metafísicas implicadas nas tradicionais categorias, geralmente dicotômicas, de sujeito, subjetividade e identidade subjacentes às concepções humanistas que alimentaram a filosofia e as ciências do homem nos últimos séculos e que hoje, inadiavelmente, reclamam por uma revisão radical” (SANTAELLA, 2007).
\end{abstract}

Observamos, portanto, que o conceito de pós-humano remete à não-separação do humano em relação ao seu ambiente ou, mais pontualmente, à superação da distinção entre corpo e mente - basilares para a construção do pensamento moderno - proposta por Descartes (2001). Ao traçarmos uma associação entre as diversas implicações relatadas pela presença ubíqua da internet e o cenário contemporâneo experienciado pelo humano como realidade, não obstante identificamos a necessidade de se reconhecer que, de modo generalizado, a cultura, a economia, a política e os demais campos das relações em sociedade - em destaque, a educação - existem como objetos imersos em um complexo heterogêneo de relações sociotécnicas ${ }^{11}$. Assim, nos termos de Robert Pepperell (2003, p. 22), consideramos que a era contemporânea elucida a improbabilidade de se estabelecer fronteiras suficientemente discerníveis sobre o que, de fato, separa o corpo da mente, ou mesmo o que diferencia, na formação da realidade para o sujeito, o humano da máquina.

Ao sujeito, o entrelaçamento entre as realidades do online e do offline, propiciado sobretudo pelo acoplamento humano à dispositivos informacionais, pode representar, concomitantemente, uma ampliação e um estreitamento da sua capacidade de autodeterminação no estabelecimento das suas relações no mundo. Aqui, nos referimos especificamente àquilo com que o sujeito efetivamente interage no âmbito da sua experiência, englobando outros humanos, mas principalmente aquilo que lhe fundamenta epistemológica e simbolicamente. Em razão disso, apontamos para as características de randomicidade e de autoorganização das redes sociais mediadas interativamente por plataformas digitais, operadas numa lógica de inflow e outflow onde, continuamente, usuário e plataforma se retroalimentam

11 Nesse sentido, apesar de não utilizarmos como proposta teórico-metodológica, aproximamo-nos conceitualmente da Teoria Ator-Rede de Bruno Latour (2012). 
dos dados os quais ambos coproduzem (SANTAELLA; CARDOSO, 2014). Nessa medida, em concordância com a proposta de Santaella (2016, p. 45), alertamos para a necessidade de, sob uma perspectiva interdisciplinar, buscarmos horizontes para compreender as implicações propiciadas por dispositivos permanentemente conectados à internet nos métodos tradicionais de construção do conhecimento.

Neste prisma, partimos de uma postura crítica à modernidade, que evidencia a insuficiência epistemológica da divisão sujeito/objeto, para focalizarmos nossas reflexões no contexto da educação e das práticas pedagógicas. Contemplamos nesse questionamento tanto as práticas da educação formal quanto os processos de educação não-formal (GASPAR, 2002), tendo como ponto de partida a cibercultura como desafio para pensar a constituição do sujeito dito pós-humano frente aos processos educativos.

\section{Abordagens empregadas por práticas curriculares tradicionais diante do contexto sociotécnico contemporâneo}

Considerando o contexto sociotécnico contemporâneo abordado na seção anterior, o qual contempla a chamada era da internet ubíqua e o sujeito pós-humano, trazemos para o centro da reflexão um aprofundamento na questão educacional, isto é, como se configuram as práticas curriculares em meio a esse cenário. Atualmente, se apresenta como premissa e, de certa forma, como senso comum, que é necessário buscar alternativas às metodologias ou posturas de ensino ditas como tradicionais, a fim de buscar um maior protagonismo dos estudantes e de integrar as novas tecnologias ao cotidiano de aulas. Tais metodologias tradicionais apresentam uma configuração que, em resumo, conta com uma supervalorização do professor como autoridade, sendo o detentor e transmissor do conhecimento, o qual consta como imóvel e imutável, a ser transferido aos alunos, que devem absorvê-lo e acumulá-lo.

Essa postura tradicional influencia desde a dinâmica das aulas — um professor expondo conteúdos e sendo escutado frente a muitos alunos ouvindo e fazendo anotações até a sua arquitetura - alunos sentados, enfileirados em direção a um professor em pé. Assim, uma aula pode ser tradicional mesmo com o uso de tecnologias das mais atuais, visto que a premissa expositiva se adequa tanto à lousa quanto a apresentações digitais, ao uso de vídeos, jogos, realidade aumentada, dentre outras abordagens mais recentes. Contudo, é importante ressaltar que a aula expositiva não é a vilã ou o único problema na sala de aula, mas o que colocamos, assim como outros autores na educação (NETO; SOSTER, 2017), é que esta não 
é a única estratégia para se abordar na sala de aula com os estudantes, principalmente com as mudanças na constituição dos sujeitos que viemos apontando.

Dito isso, voltamos os estudos à área que busca pensar a relação das tecnologias com a educação, chamada de Informática na Educação ou Informática Educativa, a qual nasceu no Brasil na década de 70 com experiências em universidades (VALENTE; ALMEIDA, 1997) sob influência de Papert (1980), que propôs um uso de tecnologia que objetivava o estudante como protagonista. Conforme o autor, a aprendizagem é mais efetiva quando um estudante se engaja em construir um objeto que possa ser público, compartilhado, discutido, apresentado aos colegas e professores, seja um objeto concreto ou um software, por exemplo. RABBE et al. (2016) colocam que a introdução da informática nas escolas tinha como premissa uma mudança de ordem pedagógica, a qual o contexto escolar ainda não estava preparado para efetivar. Em contraponto a tal período, a atualidade mostra que $85 \%$ das escolas brasileiras possuem laboratório de computadores e, dessas, $92 \%$ possuem alguma forma de conexão com a internet (TIC EDUCAÇÃO, 2014), o que se soma ao número de smartphones no Brasil, que já ultrapassou 220 milhões de aparelhos em 2018 (FGV-SP, 2018), aspecto que tem desencadeado mudanças comportamentais. Além disso, segundo a pesquisa TIC Educação e TIC Kids Online Brasil (CETIC.BR, 2017), o número de crianças e adolescentes entre 9 e 17 anos que são usuários de internet no Brasil chega a 85\% em 2017, com o celular sendo o meio mais usado (93\%), seguido de computador (53\%), televisão (25\%) e videogame (16\%). Nesse cenário, hoje, de modo geral, já estamos convencidos de que o uso de tecnologias na educação é necessário, e que o debate agora está mais focado em como fazer bom uso de tecnologias, em como formar professores para fazer essa mediação, em que papéis a tecnologia pode tomar e em quais posturas de ensino-aprendizagem podem potencializar.

Ainda segundo a pesquisa (CETIC.BR, 2017), se percebe que $76 \%$ dos respondentes pesquisou na internet para fazer trabalhos escolares e $64 \%$ pesquisou na internet por curiosidade ou vontade própria, além de que $51 \%$ leu ou assistiu a notícias online. Quanto ao uso de celulares em atividades educacionais, os alunos do Ensino Médio são os que mais usam o celular (75\%), seguido do $9^{\circ}(64 \%)$ e do $5^{\circ}$ ano $(30 \%)$ do Ensino Fundamental, num total de $60 \%$ dos alunos da rede particular e $53 \%$ da rede pública. O número de professores que usa celular em atividades com os alunos vem crescendo, atingindo em 2017 o patamar de 69\% (particular) e 53\% (pública). A rede social mais utilizada é o WhatsApp (66\% na rede particular e 52\% na rede pública). Para além da sala de aula, em geral são mais os professores de redes particulares que desenvolvem interações com os alunos frente aos de redes públicas - para citar os mais frequentes, $61 \%$ frente a $44 \%$ quanto a conteúdos disponibilizados na 
internet, $53 \%$ a $41 \%$ quanto a avaliações de desempenho dos alunos, $66 \%$ a $36 \%$ quanto a tirar dúvidas de alunos na internet, $60 \%$ a $36 \%$ quanto a usar programas educativos de computador com os alunos e $53 \%$ a $23 \%$ quanto a receber trabalhos pela internet. Em termos de atividades educacionais do currículo, as que mais são executadas por alunos de escolas urbanas usuários de internet são pesquisas para a escola (86\%), trabalhos sobre um tema (80\%), pesquisas sobre conteúdos expostos pelo professor (76\%), trabalhos em grupo (73\%) e estudo para provas (72\%). Já os professores das escolas urbanas usam mais a internet para solicitar trabalhos sobre temas específicos e dar aulas expositivas (48\%), solicitar trabalhos em grupo e exercícios (40\%), bem como promover debates ou apresentações (35\%), dentre outros.

A partir dos dados, mesmo que sejam uma amostra - não imediatamente generalizável — da realidade brasileira, vemos que cada vez mais os jovens estão usando a internet, e que esse uso se acentua conforme se tornam adolescentes. Além disso, os alunos de redes particulares, como já é esperado, têm mais acesso a internet e a usam de forma mais frequente tanto em relação às atividades escolares quanto na vida cotidiana. Referente às interações de professores com alunos, é interessante notar que há certa discrepância, pois vemos que os estudantes usam a internet em trabalhos escolares e em pesquisas por curiosidade própria com mais frequência do que o solicitado pelos professores para atividades educacionais. Há uma possível lacuna, que mostra certa tendência dos estudantes de se utilizar dos meios possíveis - sendo a internet um dos mais usados — para potencializar o seu trabalho escolar, tanto quanto solicitado de forma curricular ou, como vemos, ainda mais que isso. Assim, se mostra possível um espaço para ampliação do uso das tecnologias em práticas curriculares, o que é reforçado pelas tendências de crescimento desse uso nos últimos anos apresentadas pela pesquisa.

Ainda para além do mero uso das tecnologias, podemos considerar que estamos em um período no qual se tem valorizado mais as vertentes pedagógicas que buscam o protagonismo do estudante na sua aprendizagem. Mas nesse contexto educacional em que se aumenta a apropriação de plataformas digitais, da internet, das mídias sociais, podemos questionar de que forma isso transforma, de fato, a educação, em termos paradigmáticos, haja vista que os usos mais frequentes da internet pelos professores de escolas urbanas se focaram em aulas expositivas e solicitação de trabalhos e exercícios. O que depreendemos disso é que as diversas iniciativas - em si, positivas — para fomentar um uso de tecnologias junto à educação ainda não acarretaram em uma mudança de paradigma que tome como base e que proponha como protagonista o estudante, algo possivelmente em vias de ocorrer, mas que por 
ora ainda enfrenta "usos atrelados a práticas ultrapassadas de transmissão de conhecimento" (RABBE et al., 2016, p. 13).

Além desse questionamento, soma-se o contexto desse dito "novo" sujeito póshumano, cuja incorporação de dispositivos informacionais conectados a uma dimensão virtual (digital) no cotidiano já é naturalizada, e que transita entre real e virtual, numa indistinção entre on e offline. O uso de tecnologias deve considerar esse cenário como provável enquanto cotidiano da maioria dos estudantes, tendo-o como um pressuposto, uma premissa e um requisito para se poder pensar não apenas atividades educacionais, mas sim um paradigma que possa estruturar de forma curricular as práticas pedagógicas dentro e para fora da sala de aula. Aprofundando nessa questão, tem-se como base, a partir da internet, a possível ampliação ou estreitamento da capacidade desses sujeitos de autodeterminação no estabelecimento das suas relações no mundo, ou seja, há tanto potencialidades quando fragilidades no direcionamento frente ao uso tecnológico de forma indiscriminada. Mesmo nas atividades mais realizadas por estudantes, como as de pesquisa, já é possível se deparar com questões inerentes à estrutura da rede que levam às possíveis "bolhas de opinião" ou "câmaras de eco", ou seja, sem um conhecimento próprio de como atuar na internet, pode-se mesmo não se entender como pesquisar e como, enfim, aprender a partir desse processo. Isso sem ainda entrar em outras questões abordadas pela pesquisa já citada (CETIC.BR, 2017), como a parcela de estudantes, maior que um terço, que já viram alguém ser discriminado na internet, além do possível acesso a conteúdos instrutivos de como ficar muito magro, como machucar a si mesmo, como cometer suicídio, dentre outros possíveis riscos no acesso à rede.

Ainda expandindo a reflexão, podemos pensar em que medida os materiais escolares e as estratégias de ensino correspondem à formação informal desse "novo" sujeito. Por formação informal (GASPAR, 2002) — também colocada como não-formal —, pode ser citado como exemplo o estudante que está na sala de aula, aprendendo junto à turma e ao professor, e ao mesmo tempo está na internet, informalmente buscando informações, e sujeito a todo tipo de conteúdos que podem, inclusive, ser opostos ao que se vê na sala de aula. Questiona-se assim, em última instância, o próprio conhecimento e como se lida com ele neste cenário de imersão tecnológica na sociedade, na medida em que a construção e a posterior legitimação do conhecimento como saber, observar e modo de conhecer o mundo encontra-se cada vez mais "fluída", isto é, sem a mediação protagonista do campo formal-institucional tradicional/moderno.

Outra questão a ser considerada é a de que muitas aulas publicadas no site de vídeos YouTube, as quais compõem uma considerável parte dessa formação informal, são, na 
verdade, de caráter muito tradicional, ou seja, aulas expositivas, apresentando uma exposição de conteúdo feita por um(a) professor(a), com o suporte de materiais como imagens e vídeos digitais e, por vezes, inclusive, o uso de uma lousa. Questionamos, também, o porquê de isso poder ser considerado como agradável e interessante pelos jovens, frequentemente vistos nos comentários da plataforma agradecendo pelos conteúdos, e qual a relação dessas aulas com a educação formal. Percebemos empiricamente que muitas vezes se busca em vídeos na internet a revisão de conteúdos para provas e trabalhos, em vez de se usar os materiais de aula anotações, livros, textos etc. De certa forma, podemos supor que o contexto dos vídeos na internet é mais instigante do que o contexto da sala de aula.

No YouTube, podemos perceber um direcionamento ao fato de que o usuário sente que está escolhendo, buscando dentre várias opções a que mais lhe interessa, além de que os vídeos podem ser assistidos no horário de sua preferência, e da forma que convir — sozinho ou em grupo, no celular, no tablet, no computador, com fone ou caixas de som, pode ler os comentários ou não, etc. Isso vai de encontro à sala de aula, que traz uma carga de obrigação, de rotina imposta, e de escolha limitada, visto que os trabalhos são impostos, a turma é sempre a mesma e possivelmente traz distrações externas e uma dinâmica específica com o professor, diferente de um envolvimento individual com diversos vídeos, por exemplo. Disso depreendemos que grande parte da discussão metodológica em torno das aulas na área da educação se constitui como uma busca por contornar um paradigma tradicional e problemático — aulas rotineiras, monótonas e diárias; a arquitetura da sala de aula; a necessidade de cumprir um cronograma rigoroso de conteúdos; as exigências para o vestibular no caso do Ensino Médio; afora outros exemplos, enfim, a escola como uma rotina imposta, tradicional e difícil de ser transformada.

Se há tanta discussão em torno de como transformar uma aula tradicional e torná-la mais dinâmica, enfatizando o estudante como protagonista, é porque justamente ela ainda não é dinâmica assim e não tem o protagonismo do estudante como base, tanto por questões referentes à própria aula mas também por questões referentes ao próprio sistema da escola, ancorado nesse paradigma tradicional. O que se pode perceber é que não é só a dinâmica da aula que importa em termos de considerar o aluno como um protagonista e de pensar as tecnologias na educação de uma forma que contemple as mudanças provocadas nos sujeitos pelo contexto da internet ubíqua, mas sim todo o paradigma vigente — justamente é isso que se vê quando os alunos preferem assistir no YouTube a exposições de conteúdos que podem ser tão tradicionais ou monótonas quanto as suas piores aulas. Portanto, podemos apontar ainda uma desconexão da própria educação com a forma de se relacionar com o conhecimento 
que as crianças e adolescentes - e mesmo nós, professores, que revisamos conteúdos no YouTube - têm desenvolvido hodiernamente.

\title{
4. Considerações finais: na transição do sujeito da razão para o da performance, o paradigma tradicional em questionamento
}

O termo "performance", em inglês, significa "atuação", "desempenho", "rendimento", mas a partir da década de 1950, o conceito começou a assumir significados mais específicos, especialmente nos campos das artes e das ciências humanas, como uma ideia de compreender a dicotomia "arte versus vida". No campo da antropologia, Richard Schechner (1988, p. 29) afirma que a performance consiste na atividade "feita por um indivíduo ou grupo na presença de e para outro indivíduo ou grupo”. Nessa perspectiva, Diana Klinger (2008, p. 20), a partir de estudos fundamentados na obra de Derrida, questiona o que é a representação de um sujeito em si mesmo, e diz que antes de saber como e o que traduzir

\begin{abstract}
por representação, devemos nos perguntar pelos conceitos de tradução e de linguagem, conceitos dominados freqüentemente pelo conceito de representação, seja interlingüística, intralingüística ou inter-semiótica (entre linguagens discursivas e não-discursivas) na arte, por exemplo. Em cada caso nos encontramos com pressuposto, ou o desejo, de uma identidade de sentido invariável, que regula todas as correspondências. Esse desejo seria o de uma linguagem representativa, linguagem que representaria um sentido, um objeto, um referente, que seriam anteriores e exteriores a essa linguagem. Sob a diversidade das palavras de línguas diferentes, sob a diversidade dos usos da mesma palavra, e sob a diversidade dos contextos $[\ldots]$
\end{abstract}

Então, é a partir de uma crítica à noção tradicional de performance e sujeito que podemos pensar sobre a formação do sujeito no contexto ciber, pós-humano, o qual impreterivelmente remete a uma matriz destituída de uma essência última. Nota-se que, contemporaneamente, ao se ter em vista a hibridicidade constituída entre os reais on/offline, não há como atribuir significados de acordo com o que um determinado sujeito é, mas apenas discernir as representações pelas quais este sujeito articula a(s) sua(s) identidade(s) em diferentes contextos. Nesse caso, ilustramos que a construção performativa de um determinado sujeito adquire forma quando há a ocorrência — isto é, um desempenho performativo - de uma autorrepresentação em ambientes digitais, compreendendo que a mediação com a percepção de um outro se dá por meio do caráter atribuído a, por exemplo, sua foto de perfil em uma plataforma de digital.

Essa lógica exposta, todavia, não denota que a performance possa ser reconhecida meramente por fatores objetivos e/ou contextuais. Conforme propõe Santaella (2010), as tecnologias continuamente conectadas ao ciberespaço estão produzindo novas subjetividades, cada vez mais maleáveis, adaptativas a diferentes ambientes e que encontram-se em mutação 
permanente. Portanto, entendemos que o caráter performático da formação do sujeito exerce, simbolicamente, uma espécie de "encenação de si mesmo", de acordo com o contexto social, cultural ou educacional da plataforma em questão, confundindo as próprias noções de verdade e ilusão. Por exemplo, o Twitter - uma plataforma de redes sociais que funciona como um microblogging - permite que usuários enviem e recebam atualizações pessoais de seus "seguidores" por meio de microtextos de até 280 caracteres - denominados tweets. Percebemos que o modo como um sujeito se apresenta nessa plataforma difere-se de como se apresenta no Instagram, uma plataforma de compartilhamento de fotos e vídeos entre usuários que, dentre os seus recursos particulares, permite a aplicação de filtros nas imagens e o seu compartilhamento com seguidores.

A relação dessa dinâmica performática na constituição identitária, e mesmo epistêmica, da constituição do sujeito encontra, de maneira mais nítida, respaldo na sua formação educacional a partir do exemplo citado do YouTube. Conforme apresenta a pesquisa de Paolillo (2018), plataformas como o YouTube permitem a emergência do entrelaçamento de diversas visões de mundo inicialmente isoladas entre si, em virtude da operacionalidade aberta da plataforma à participação opinativa de seus usuários, seja na forma de comentários ou através da criação de conteúdos próprios. Assim, percebemos a ocorrência de uma performance colaborativa entre diferentes sujeitos, capaz de difundir, em caráter informal, determinadas visões de mundo cuja consequência, não raro, resulta no questionamento de conhecimentos consolidados na educação formal-institucional, a exemplo do movimento terraplanista. Nesse sentido, remetendo ao que Santaella (2010) classifica como "aprendizagem ubíqua", a possibilidade do exercício de controle pelo usuário de uma plataforma acerca de quais conteúdos serão vistos, embora não exclua, imediatamente, a relevância da educação formal, permite a emergência de conflitos em relação a quais conhecimentos são legítimos ou ilegítimos.

Diante do exposto, o presente trabalho apresentou uma problematização das abordagens empregadas pelas práticas curriculares tradicionais diante do contexto sociotécnico contemporâneo. Nosso principal questionamento levanta em que medida os materiais escolares, bem como as estratégias de ensino, correspondem à formação informal ou não-formal (GASPAR, 2002) de um "novo" sujeito, isto é, em reconhecimento a uma era em que a cultura contemporânea é influenciada pelas tecnologias digitais e pela internet ubíqua. Sob uma ótica do "pós-humano" (SANTAELLA, 2007), consideramos que as novas mídias modificam fundamentalmente a forma pela qual o sujeito interage com o mundo, o que resulta em novos modelos de articulação entre pensamento e linguagem. Quando pensamos a 
internet como um local colaborativo, em que muitas afirmações são dadas pelos próprios usuários, as noções de autoridade e autenticidade do conhecimento se esboroam — garante que o aprendizado não seja centralizado, nem institucionalizado. Nesse sentido, colocamos como necessário repensar, paradigmaticamente, a educação e a construção do conhecimento na contemporaneidade, como concebidos por sujeitos, constituídos enquanto criação colaborativa entre humanos, objetos não-humanos e relações mediadas.

Destacamos que, atendendo a uma realidade complexa, resultante do entrelaçamento entre as realidades correspondentes aos mundos online e offline, existe factualmente uma expansão da capacidade experiencial do (pós)humano. Em seguimento a essa lógica, entendemos que, contemporaneamente, existe a necessidade de rompimentos a concepções lineares, casuísticas e essencialistas quanto à constituição de significados, de identidades e, portanto, de conhecimentos. Trazendo a noção de performance, compreendemos que a maleabilidade constitutiva ao o que é o sujeito torna-se inerente ao processo de exposição e aquisição de novos conhecimentos. Nesse sentido, considerando a imersão do sujeito póshumano em uma realidade permeada por redes digitais, verificamos a impossibilidade daquilo que sugeriu Descartes (1641: 2017), quando propôs um exercício de esquecimento acerca dos conhecimentos adquiridos até um determinado tempo, como possibilidade epistêmica de renovação em direção à construção de novas possibilidades intelectivas. Dessa forma, não há uma saída possível, visto que a ideia de performance indica que o sujeito encontra-se permanentemente associado a uma dada realidade.

Isto posto, há a necessidade de ressaltarmos como evidente que, neste estudo, a proposta inicial não é a do apontamento de uma solução única e efetiva a um problema específico ou um cenário dificultoso, mas sim de uma problematização mais aprofundada do contexto da educação frente às diversas mudanças apontadas na cultura contemporânea. Em nossos eixos de reflexão, indicamos algumas situações que trazem transformações para as práticas pedagógicas e a necessidade de ponderá-las. Para além de tantas iniciativas consideradas como positivas, buscamos aludir a um pensamento de ordem mais estrutural, a fim de expandi-las paradigmaticamente na educação.

\section{Referências}

BONDÍA, Jorge Larrosa. Tremores: escritos sobre experiência. Belo Horizonte: Autêntica, 2017. 
BOYD, Danah. It's Complicated: The Social Lives of Networked Teens. New Haven, CT: Yale University Press, 2014. Disponível em: <https://www.danah.org/books/ItsComplicated.pdf>. Acesso em 07 jan, 2019.

CASTELLS, Manuel. A sociedade em rede. 11 a ed. São Paulo: Paz e Terra, 2008.

CASTELLS, Manuel. O poder da comunicação. Rio de Janeiro: Paz e Terra, 2015.

Centro Regional de Estudos para o Desenvolvimento da Sociedade da Informação (CETIC.br) / CGI.br / NIC.br. TIC Educação e TIC Kids Online Brasil 2017. São Paulo, 21 nov. 2018. Disponível em: <https://cetic.br/media/analises/Apresentacao-lancamento-das-publicacoesdas-pesquisas-tic-educacao-e-tic-kids-online-brasil-2017.pdf>. Acesso em: 07 jan. 2019.

DENARDIS, Laura. The Global War for Internet Governance. New Haven and London: Yale University Press. 2014

DESCARTES, René. Meditations on First Philosophy. Trad. J. Veitch. Toronto: Our Open Media, 2017. Publicação original em 1641. Disponível em: <http://bradleymurray.ca〉. Acesso em: 08 jan. 2019.

DESCARTES, René. O Discurso do Método. $3^{\mathrm{a}}$ ed. São Paulo: Martins Flores, 2001.

RESNER, Eli; HERRING, Susan. Emoticons and illocutionary force. In: RIESENFELD, Dana; SCARAFILE, Giovanni (Org.). Philosophical dialogue: Writings in honor of Marcelo Dascal. London: College Publication, 2012. p. 59-69.

FUNDAÇÃO GETÚLIO VARGAS DE SÃO PAULO (FGV-SP). Escola de Administração de Empresas de São Paulo. 29a Pesquisa Anual de Administração e Uso de Tecnologia da Informação nas Empresas. $2018 . \quad$ Disponível em: <https://eaesp.fgv.br/sites/eaesp.fgv.br/files/pesti2018gvciappt.pdf>. Acesso em: nov. 2018.

GASPAR, Alberto. A educação formal e a educação informal em ciências. Massarani L., Moreira IC, Brito F. orgs, p. 171-183, 2002. Disponível em: <https://goo.gl/Pth5ZQ>. Acesso em: 08 jan. 2019.

HARAWAY, Donna. A Cyborg Manifesto. Minnesota: University of Minnesota Press, 2016. Disponível em: 〈https://goo.gl/Z1zw21〉. Acesso em: 07 jan, 2019.

HERRING, Susan. Computer-mediated discourse. In: TANNEN, Deborah; HAMILTON, Heidi; SCHIFFRIN, Deborah (Org.). Handbook of discourse analysis. Oxford: Blackwell, 2001.

KLINGER, Diana. Escrita de si como performance. Revista Brasileira de Literatura Comparada, n. 12, 2008, p. 11-30.

LATOUR, Bruno. Reagregando o social: uma introdução à teoria do Ator-Rede. Salvador: EDUFBA-Edusc, 2012.

LEMOS, André. Apropriação, desvio e despesa na cibercultura. Revista Famecos. Porto Alegre, n. 15, p. 44-56, ago, 2001. Disponível em: <http://revistaseletronicas.pucrs.br/ojs/index.php/revistafamecos/article/view/3119/2392>. Acesso em 06 jan, 2019. 
LEMOS, A. Ciberespaço e tecnologias móveis: processos de territorialização e desterritorialização na cibercultura. Baurú: ENCONTRO ANUAL DA COMPÓS, 15, 2006, Baurú. Anais... UNESP, Bauru, 2006.

LEMOS, André. Mídias Locativas e Vigilância: sujeito inseguro, bolhas digitais, paredes virtuais e territórios informacionais. In: FIRMINO, Rodrigo. BRUNO, Fernanda; KANASHIRO, Marta. Vigilância, Segurança e Controle Social na América Latina. Curitiba: PUCPR, 2009, p. 621-648. ISSN 2175-9596

LEMOS, André; LÉVY, Pierre. O Futuro da internet: Em direção a uma ciberdemocracia planetária. $1^{a}$ ed. São Paulo: Paulus. 2010.

LÉVY, Pierre. Cibercultura. $1^{\text {a }}$ ed. São Paulo: Editora 34, 1999.

MISKOLCI, Richard. Sociologia Digital: notas sobre pesquisa na era da conectividade. Contemporanea, v. 6, n. 2, p. 275-297, jul-dez, 2016. Disponível em: <http://www.contemporanea.ufscar.br/index.php/contemporanea/article/view/525/211 >.

Acesso em 07 jan, 2019.

MORAN, José Manuel. Mudando a educação com metodologias ativas. In: SOUZA, C. A. \& MORALES, O. E. T. (Orgs). Convergências midiáticas, educação e cidadania: aproximações jovens. Vol. II. PG: Foca Foto-PROEX/UEPG, 2015. p. 15-32. [Mídias Contemporâneas]

NETO, Octavio M.; SOSTER, Tatiana S. (orgs.). Inovação acadêmica e aprendizagem ativa [recurso eletrônico]. Porto Alegre: Penso, 2017.

O'HARA, Kieron; HALL, Wendy. Four Internets: The Geopolitics of Digital Governance. CIGI Papers, n. 206, p. 128, dez, 2018. Disponível em: <https://www.cigionline.org/publications/four-internets-geopolitics-digital-governance>.

Acesso em 07 jan, 2019.

PAOLILLO, John C.. The Flat Earth phenomenon on YouTube. First Monday, [S.1.], dez. 2018. ISSN $13960466 . \quad$ Disponível em: <https://firstmonday.org/ojs/index.php/fm/article/view/8251/7693>. Acesso em: 10 jan. 2019. doi:https://doi.org/10.5210/fm.v23i12.8251.

PAPERT, S. Mindstorms: children, computers, and powerful ideas. New York: Basic Books, 1980.

PARISER, Eli. O filtro invisível: o que a internet está escondendo de você. Rio de Janeiro: Zahar, 2012.

PEPPERELL, Robert. The Post-human Condition. $3^{\text {a }}$ ed. Oxford, Intellect, 2003.

RAABE, A. L. A. et al. Educação criativa: multiplicando experiências para a aprendizagem. Pipa Comunicação, 2016. 472p. (e-book)

RODRIGUES, Léo Peixoto. Há limites para a Sociologia do Conhecimento em uma "Sociedade do Conhecimento"?. In: SANTOS, Hermílio (Org.). Debates Pertinentes para entender a sociedade contemporânea. Porto Alegre: EdiPUCRS, 2010. 
SAMPIERI, R; COLLADO, C; LUCIO, M. Metodologia de Pesquisa. Porto Alegre: Penso Editora, 2013.

SANTAELLA, Lúcia. Pós-humano — por quê?. Revista USP, São Paulo, n 74, p. 126-137, jun-ago, $2007 . \quad$ Disponível em: $<$ https://www.revistas.usp.br/revusp/article/download/13607/15425>. Acesso em 07 jan, 2019.

SANTAELLA, L. Aprendizagem ubíqua substitui a educação formal? Revista de Computação e Tecnologia da PUC-SP, v. 2, n. 1, 2010. Disponível em: $<$ https://revistas.pucsp.br/index.php/ReCET/article/download/3852/2515>. Acesso em 12 jan, 2019.

SANTAELLA, Lúcia. Por uma epistemologia antidualista. In: LOPES, Maria Immacolata Vassallo de (Org.). Epistemologia da Comunicação no Brasil: trajetórias autorreflexivas. São Paulo: ECA USP, 2016. p. 35-48.

SANTAELLA, Lúcia; CARDOSO, Tarcísio. Para inteligir a complexidade das redes. Revista Famecos, Porto Alegre, v. 21, n. 2, p. 742-765, mai-ago, 2014. Disponível em: <http://revistaseletronicas.pucrs.br/ojs/index.php/revistafamecos/article/view/15923>.

Acesso em 07 jan, 2019.

SCHECHNER, Richard. Performance theory. New York: Routledge, 1988.

TIC EDUCAÇÃO 2014: Pesquisa sobre o uso das tecnologias da informação e comunicação nas escolas brasileiras [livro eletrônico]. Survey on the use of information and communication technologies in brazilians schools: ICT education 2014. Coord. exec. e ed. Alexandre F. Barbosa. São Paulo: Comitê Gestor da Internet no Brasil, 2015. Disponível em: <https://cetic.br/media/docs/publicacoes/2/TIC_Educacao_2014_livro_eletronico.pdf>.

Acesso em: 15 dez. 2018.

VALENTE, José Armando. ALMEIDA, Fernando José de. Visão analítica da Informática na Educação no Brasil: A questão da formação do professor. Revista Brasileira de Informática na Educação, n. 1, 1997. 